\title{
Silicon oxycarbide-based composites produced from pyrolysis of polysiloxanes with active Ti filler
}

\author{
H. Deniz Akkaş ${ }^{a}$, M. Lütfi Öveçoğlu ${ }^{b}$, Metin Tanoğlu ${ }^{a}$,* \\ a İzmir Institute of Technology, Department of Mechanical Engineering and Materials Research Center, Gülbahçe Campus, 35430 Urla, İzmir, Turkey \\ ${ }^{\mathrm{b}}$ Istanbul Technical University, Department of Metallurgy and Materials Engineering, Maslak, Istanbul, Turkey
}

Received 30 April 2005; received in revised form 8 August 2005; accepted 17 August 2005

Available online 3 November 2005

\begin{abstract}
Phenyl (PPS) and methyl (PMS) containing polysiloxanes were pyrolyzed at elevated temperatures (900-1500 $\left.{ }^{\circ} \mathrm{C}\right)$ under argon atmosphere to investigate the phase developments within the polymers. It was found that pyrolysis of the polymers under inert atmosphere up to $1300{ }^{\circ} \mathrm{C}$ leads to amorphous silicon oxycarbide $\left(\mathrm{SiO}_{x} \mathrm{C}_{y}\right)$ ceramics. Conversions at higher temperatures results in the transformations into the crystalline $\beta$-SiC phases. Ceramic matrix composites (CMCs) were developed based on the active filler controlled pyrolysis (AFCOP) of polysiloxanes with active Ti filler additions. CMC monoliths were prepared with 60-80 wt.\% of active Ti particulates blended into polymer precursors. Green bodies of the composites were made by warm pressing under $15 \mathrm{MPa}$ pressure and ceramics were obtained by pyrolysis at elevated temperatures between 900 and $1500^{\circ} \mathrm{C}$ under argon atmosphere. The results showed that due to the incorporation of active Ti fillers, formation of crystalline phases such as $\mathrm{TiC}$, TiSi, and $\mathrm{TiO}$ occured within the amorphous matrix due to the reactions between the $\mathrm{Ti}$ and the polymer decomposition products. The microstructural and mechanical characterization results of the composites are presented within the paper.
\end{abstract}

(C) 2005 Elsevier Ltd. All rights reserved.

Keywords: Precursors-organic; Composites; Microstructure-final; X-ray methods; Hardness; SiOC

\section{Introduction}

Ceramic materials synthesized from organosilicon polymer precursors through low-temperature routes such as sol-gel process or polymer pyrolysis have recently gained considerable attention. This is due to their several advantages over the conventional techniques such as hot pressing and sintering. It includes the applicability of versatile plastic shaping technologies to produce complex shapes, microstructural control capabilities, and low temperature processing. ${ }^{1-12}$ Because of their high thermal and chemical stability, resistance to thermal shock, low density and high hardness, these ceramics have been recently employed as high temperature structural materials. ${ }^{2,8,9}$ They have potential applications such as lightweight high temperature structural materials, fibers, coatings, catalyst supports, and

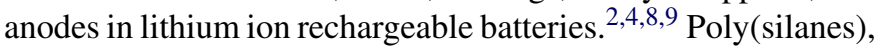
-(carbosilanes), -(silazanes), and -(siloxanes) have been the most

\footnotetext{
* Corresponding author. Tel. +90 232750 6597; fax: +90 2327506505 .

E-mail address: metintanoglu@iyte.edu.tr (M. Tanoğlu).
}

studied precursors due to their commercial availability and high ceramic yields. By pyrolysis of preceramic precursors such as polysiloxanes, silicon oxycarbide ( $\mathrm{SiOC}$ ) glasses, that contain silicon atoms bonded to oxygen and carbon randomly, can be produced. ${ }^{7,12,13}$ Polysiloxane-derived silicon oxycarbide glasses have random three dimensional arrangement of tetrahedral silicon atoms bonded to carbon and oxygen. Thermomechanical properties of the silica glasses can be improved with the replacement of divalent oxygen atoms by tetravalent carbon atoms in silica structure. . $^{1,7}$

Main drawback of the polymer pyrolysis technique is the formation of porosity within the bulk ceramic components due to evaporation of volatiles from the polymer precursor. Due to inherent density increase and ougassing of the organic matter, formation of pores and cracks may occur. To compensate these effects and to control shrinkage, crack and pore formation, a relatively new concept, active filler controlled polymer pyrolysis process (AFCOP) has been developed by several researchers. ${ }^{4-9,13}$ In this method, the polymer is partially filled with inert or active particles in order to reduce the shrinkage and to allow the fabrication of bulk, crack free ceramics. By 
incorporation of the active fillers, reactions between the active particles and the precursor occur, which typically result in a volume expansion of the reaction product, as compared to the starting compounds. This expansion may counteract the shrinkage during densification and can lead to near-net shaped crack-free components. Suitable active fillers are elements or compounds such as $\mathrm{Al}, \mathrm{B}, \mathrm{Si}, \mathrm{Ti}, \mathrm{CrSi}_{2}$, and $\mathrm{MoSi}_{2}$ to obtain carbide, nitride, or oxide reaction products. ${ }^{4,6,7,13}$

In the present work, phenyl and methyl containing polysiloxanes were pyrolyzed by the addition of active Ti particles to develop SiOC-based CMCs. CMC composite monoliths were fabricated with the addition of 60-80 wt.\% of Ti fillers by warm pressing under $15 \mathrm{MPa}$ pressure and pyrolysis at elevated temperatures between 900 and $1500{ }^{\circ} \mathrm{C}$ under inert argon and reactive nitrogen atmospheres. Effects of filler weight fraction and pyrolysis temperature on the microstructural developments were investigated by XRD and SEM-EDX. Mass losses and densification behavior of the CMCs were measured to investigate the effect of AFCOP. Mechanical characterization of the samples with and without filler addition was done by Vickers Indentation tests. In addition, phenyl and methyl containing siloxanes were pyrolyzed without $\mathrm{Ti}$ addition under $\mathrm{Ar}$ at $900-1500^{\circ} \mathrm{C}$ to monitor the organic-inorganic conversions and phase developments from the polymer precursors.

\section{Experimental procedure}

\subsection{Materials}

Two different commercially available preceramic polymers, poly(phenyl)siloxane (PPS) (H62C, Wacker Chemie, GE) and poly(methyl)siloxane (PMS) (MK, Wacker-Belsil, GE) were used. PPS, solvent free liquid resin that contains platinum catalyst, was used as received. PPS cures by the influence of heat and platinum catalyst. PMS is a solid solvent free resin and mixed with $\mathrm{Zr}$-acetylacetonate (1.5 wt.\%) as catalyst for crosslinking. As the active filler, Ti with particle size of $-149 \mu \mathrm{m}$ was used.

\subsection{Processing of neat silicon oxycarbide ceramics}

To monitor the thermal transformations of the preceramic polymers neat samples without any filler additions were prepared. Fig. 1 shows the processing stages to prepare ceramics without filler addition and composite (CMC) samples as well. For PMS system, based on the procedure developed by Harshe et al., ${ }^{7}$ the polymer in the form of solid powder was dissolved in toluene and the catalyst (Zr-acetylacetonate) in the liquid form was added by $1.5 \mathrm{wt} . \%$ to the solution. The solution was blended shortly by a spatula and then the toluene was evaporated under vacuum using desiccators. Polymers (PPS or PMS after addition of catalyst and solvent evaporation) were vacuumed for half an hour, casted in moulds and cured in an oven at $220^{\circ} \mathrm{C}$ under open-air atmosphere. The cured parts were machinable with convenient tools (cutting, milling, etc.). Pyrolysis of the samples took place in a tubular furnace operated under inert argon atmosphere at various temperatures $\left(900-1500^{\circ} \mathrm{C}\right)$. A typical heating cycle involved heating to $400{ }^{\circ} \mathrm{C}$ at $5^{\circ} \mathrm{C} / \mathrm{min}$, holding at this temperature for $30 \mathrm{~min}$, then a second ramp to $530^{\circ} \mathrm{C}$ at $5{ }^{\circ} \mathrm{C} / \mathrm{min}$, holding at this temperature for $60 \mathrm{~min}$ and heating to the final temperatures $\left(T_{\mathrm{u}}\right)$ at $5{ }^{\circ} \mathrm{C} / \mathrm{min}$ and holding the sample for $90 \mathrm{~min}$ at $T_{\mathrm{u}}$ and finally cooling the samples to the room temperature.

\subsection{Processing of composite monoliths}

To monitor the effect of active filler controlled pyrolysis on the microstructural and mechanical properties of the ceramics, composite samples were prepared. To prepare composites, Ti powders were mixed with the polymers at 60,70 , and $80 \mathrm{wt} . \%$ to obtain green bodies (Fig. 1). For PMS system, similar to the preparation of neat samples, PMS was dissolved in toluene and $1.5 \mathrm{wt} . \%$ of the catalyst was added into the system. Blends of PPS or PMS systems were casted in metal moulds and uniaxially pressed using a warm press under $15 \mathrm{MPa}$ at $220^{\circ} \mathrm{C}$ for $2 \mathrm{~h}$ for complete curing. After cutting the specimens in the desired dimensions, green bodies were finally pyrolyzed at 900, 1100,

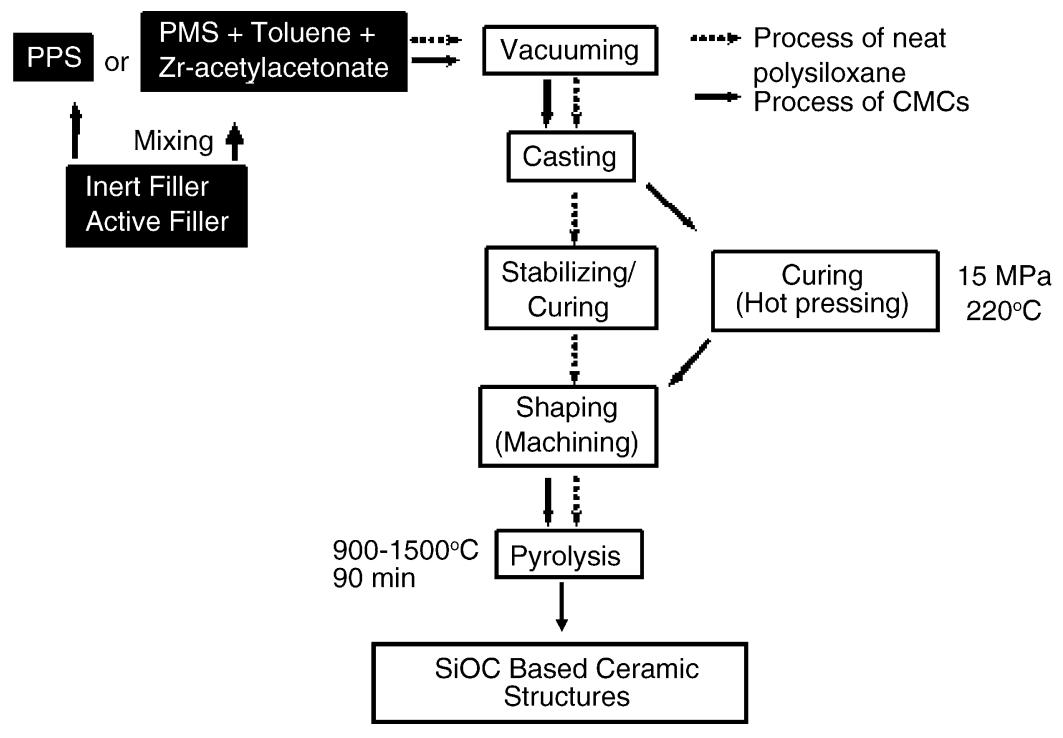

Fig. 1. CMC and neat ceramic processing with PPS and PMS precursors. 
1300, and $1500{ }^{\circ} \mathrm{C}$ under Ar, following a multi-step heating schedule described above.

\subsection{Characterization techniques}

Pyrolysis products of neat and composite samples were identified by X-ray diffraction (XRD) technique using Philips X'Pert Pro diffractometer, with $\mathrm{Cu} \mathrm{K} \alpha$ radiation. Pyrolyzed samples were first powdered and analyzed at diffraction angles $(2 \theta)$ between 5 and $70^{\circ}$. Philips XL 30SFEG field emission scanning electron microscope (SEM) and attached energy dispersive $\mathrm{X}$ ray (EDX) spectrometer was utilized for microstructural analysis on polished and fractured specimen surfaces. Polished samples were prepared by conventional metallographic techniques. Back scattered electron (BSE) images of the composite samples was also obtained to characterize the distribution of filler particles within polymer matrix. Thermal analyses were performed for determination of the mass changes and phase developments with different filler addition. Nikon Eclipse L150 optical microscope was used for the analysis of particle and pore dispersion in the composite structures on the polished samples for this purpose. Effects of the filler ratio and pyrolysis temperature on the mass losses and density changes were measured. Mass loss determinations were done based on the weight change of samples before and after pyrolysis. The hardness values of the ceramics without filler addition and composite samples were measured based on Vickers indentation test technique to investigate the effects of filler ratio and pyrolysis temperature on the mechanical properties of the samples. Zwick/Roell-TestX'Pert V9.0 machine with HV10 $(100 \mathrm{~N})$ was used on polished sample surfaces for indentation test. The indentation tip displacement rate was selected as $0.2 \mathrm{~mm} / \mathrm{min}$.

\section{Results and discussion}

\subsection{Thermal conversion of polysiloxanes}

Green bodies were obtained after polymerization of the precursors at $220^{\circ} \mathrm{C}$. The stability of green bodies indicated the network formation. The phase conversions were studied by XRD technique. Fig. 2 shows the XRD patterns of the neat poly(phenyl)siloxane (PPS) samples pyrolyzed at various tem-

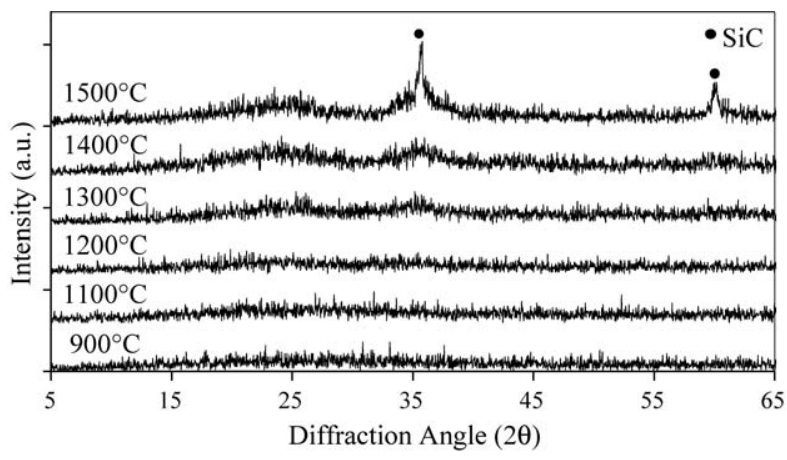

Fig. 2. X-ray diffraction patterns of the poly(phenyl)siloxane (PPS) without filler addition pyrolyzed under Ar at various temperatures.

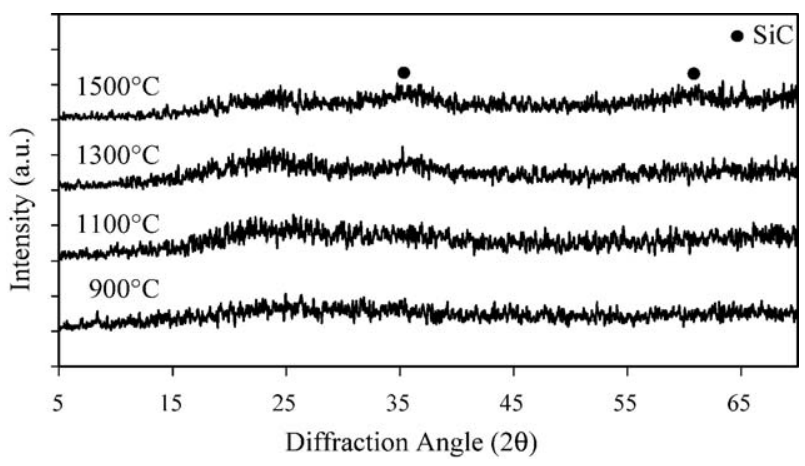

Fig. 3. X-ray diffraction patterns of the poly(methyl)siloxane (PMS) without filler addition pyrolyzed under Ar at elevated temperatures.

peratures. The patterns up to $1300^{\circ} \mathrm{C}$ are characteristic of amorphous materials of $\mathrm{SiO}_{x} \mathrm{C}_{y}$. The broad peaks with low intensities at above $1300^{\circ} \mathrm{C}$ are the diffractions associated to $\beta$-SiC. The peaks of $2 \theta=36^{\circ}$ and $60^{\circ}$ at $1500^{\circ} \mathrm{C}$ are characteristic for $\beta-\mathrm{SiC}$ crystals.

Fig. 3 shows the XRD patterns of the PMS after pyrolysis at various temperatures. As seen from the patterns the formation of $\beta$-SiC crystals occurs with low intensities at $1500{ }^{\circ} \mathrm{C}$ (at $2 \theta=36^{\circ}$ and $60^{\circ}$ ), whereas an amorphous structure is observed at lower temperatures. Similarly, it was found by Hönack and Reidel ${ }^{14}$ that SiOC does not crystallize during pyrolysis of polymethylsiloxanes (PMS, the same precursor used within the present study) up to $1100{ }^{\circ} \mathrm{C}$ in Argon. Also, Greil ${ }^{4}$ revealed that organic-inorganic transformations of polysiloxanes between 600 and $800^{\circ} \mathrm{C}$ yield an amorphous SiOC while above $800^{\circ} \mathrm{C}$ crystallization of $\mathrm{SiC}$ and $\mathrm{SiO}_{2}$ occurs between 1100 and $1600^{\circ} \mathrm{C}$. Brus et al..$^{15}$ also observed the formation of $\beta$-SiC above $1200{ }^{\circ} \mathrm{C}$ for polysiloxanes. It was reported ${ }^{16}$ for polycyclic silazens (precursor for $\mathrm{SiCN}$ ) that up to $1400^{\circ} \mathrm{C}$ amorphous residues were obtained while above this temperature in Ar the material crystallizes to yield $\beta$-SiC.

Fig. 4 shows the fracture surface SEM micrographs of the pyrolysis products of the PPS processed at various temperatures. At lower temperatures, glassy surfaces with low porosity are observed. Higher pyrolysis temperatures yield uniformly distributed submicron sized pores formed due to the density changes from the polymer to the ceramic phases. The microstructure of the PMS samples without filler addition pyrolyzed at elevated temperatures is different as compared to PPS samples. A relatively less amount of porosity is observed from PMS (Fig. 5). Different microstructure of the samples may be related to the methyl or phenyl containing structure of the precursor. SEM-EDX results indicated that the pyrolysis products of the both polymers consist of $\mathrm{Si}, \mathrm{O}$ and $\mathrm{C}$ elements, which are expected to form SiOC matrix.

\subsection{Microstructural features of SiOC-based ceramic composites}

Monolithic CMC structures with Ti addition as a filler material were prepared at various pyrolysis temperatures. Fig. 6 is a typical example showing the SE and BSE images of the green 


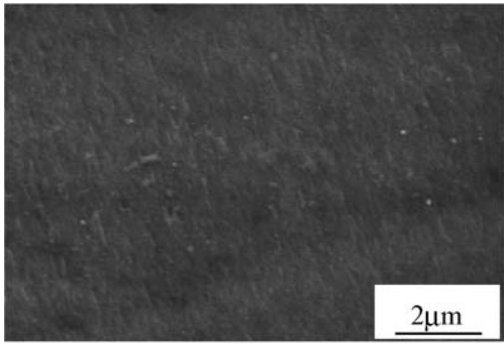

(a)

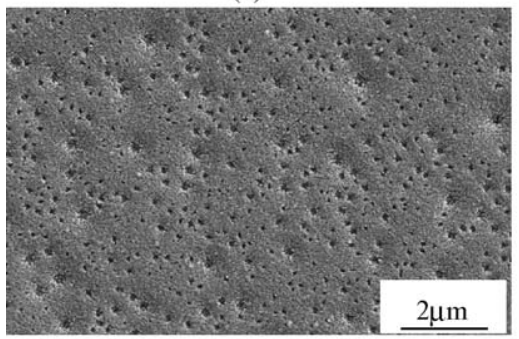

(c)

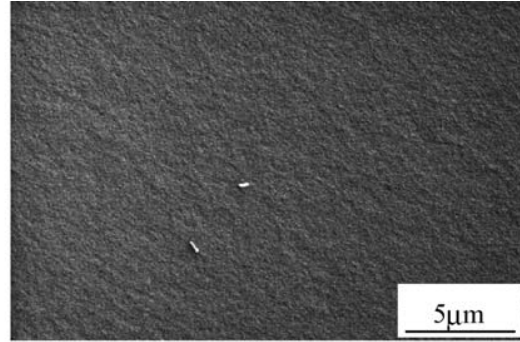

(b)

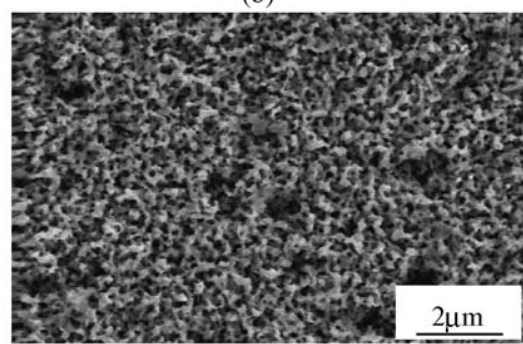

(d)

Fig. 4. Fracture surface SEM images of PPS samples without filler addition pyrolyzed at (a) $900{ }^{\circ} \mathrm{C}$, (b) $1200^{\circ} \mathrm{C}$, (c) $1400^{\circ} \mathrm{C}$, and (d) $1500^{\circ} \mathrm{C}$.

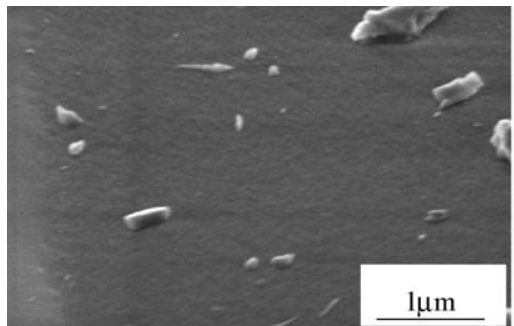

(a)

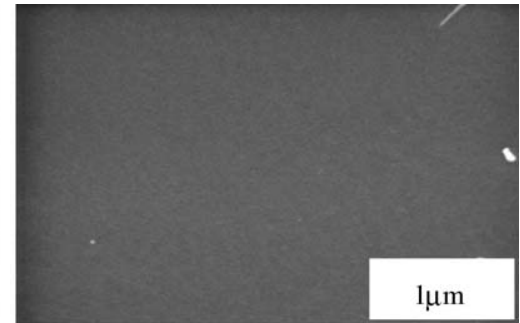

(b)

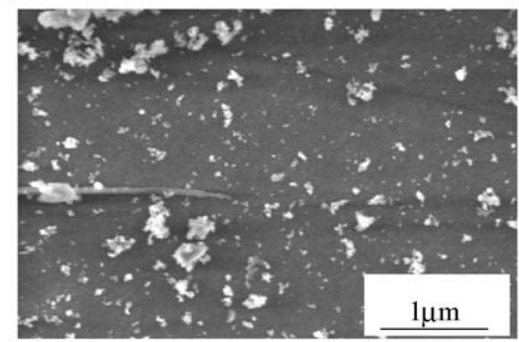

(c)

Fig. 5. Fracture surface SEM images of PMS samples without filler addition pyrolyzed at (a) $1100^{\circ} \mathrm{C}$, (b) $1300^{\circ} \mathrm{C}$, and (c) $1500^{\circ} \mathrm{C}$.

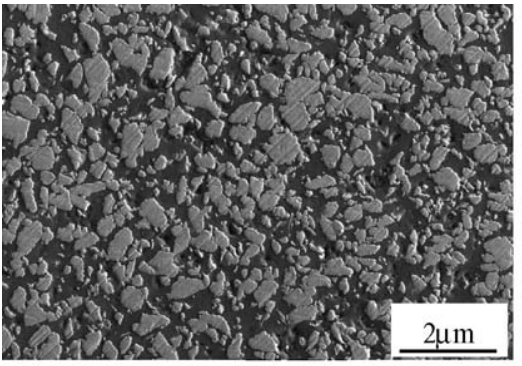

(a)

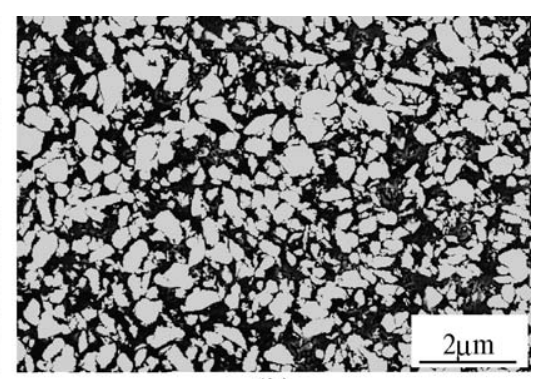

(b)

Fig. 6. SEM micrographs of $70 \mathrm{wt} . \%$ Ti /PMS system before pyrolysis: (a) SE image and (b) BSE image. 


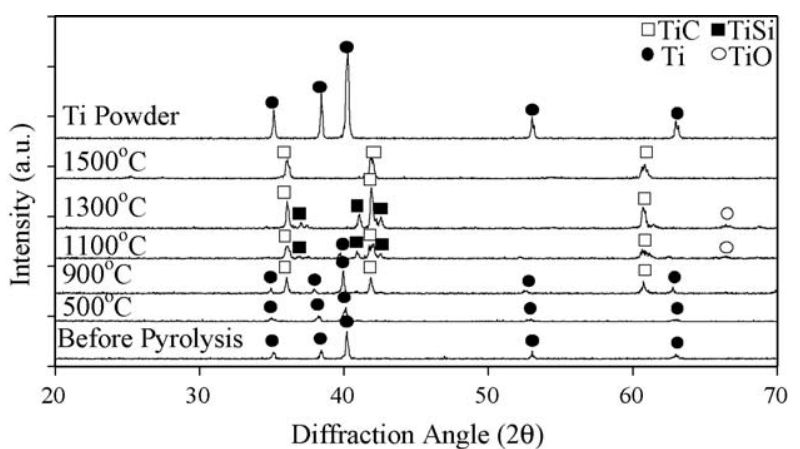

Fig. 7. X-ray diffraction patterns of $60 \mathrm{wt} . \%$ Ti/PPS pyrolyzed under Ar at various temperatures.

bodies of Ti/PMS samples before pyrolyzation. As seen from the figures, a uniform distribution of the particles within the polymer matrix is obtained by blending and warm pressing of the materials. BSE image better illustrate the distribution of Ti particles (white regions).

The effects of the filler ratio and pyrolysis temperature on the microstructural features of the composite samples were investigated. Fig. 7 shows the XRD patterns of the $60 \mathrm{wt} . \%$ active Ti particulate added CMCs prepared from PPS at various temperatures. On the same figure, XRD peaks of Ti powder and composite before pyrolysis (green body) are also shown for comparison. The results show that with the use of active Ti fillers formation of the new phases: $\mathrm{TiC}$, $\mathrm{TiSi}$ and $\mathrm{TiO}$ within the amorphous matrix occur due to the reactions between Ti and decomposition products of the polymer precursor.

Pyrolysis temperature is a critical parameter on the formation of new phases. For the green bodies without pyrolysis and CMCs pyrolyzed up to $500^{\circ} \mathrm{C}$, Ti (filler) peaks are the only phases observed. At $900^{\circ} \mathrm{C}$, the formation of $\mathrm{TiC}$ is detected. With the increasing pyrolysis temperatures, the peak intensities of the $\mathrm{TiC}$ phase slightly increase. At $1100^{\circ} \mathrm{C}$ and $1300^{\circ} \mathrm{C}$ the formation of TiSi phase is also observed. Additionally, a minor amount of $\mathrm{TiO}$ is observed at this range. At around $1500^{\circ} \mathrm{C}, \mathrm{TiC}$ is the main phase. Similarly, Greil ${ }^{4}$ found that poly(phenylsiloxane) loaded with Ti and pyrolyzed in $\mathrm{Ar}$ at $1000^{\circ} \mathrm{C}$ yields $\mathrm{TiC}$ phases together with SiOC.

To monitor the effect of the polymer type on the microstructural development, composite specimens with PMS precursor were also prepared in addition to the samples with PPS. Fig. 8 shows the XRD patterns of the $60 \mathrm{wt} . \%$ Ti-added CMC monoliths prepared from PMS at various temperatures. On this figure,

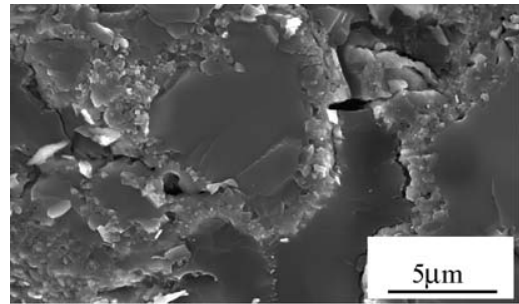

(a)

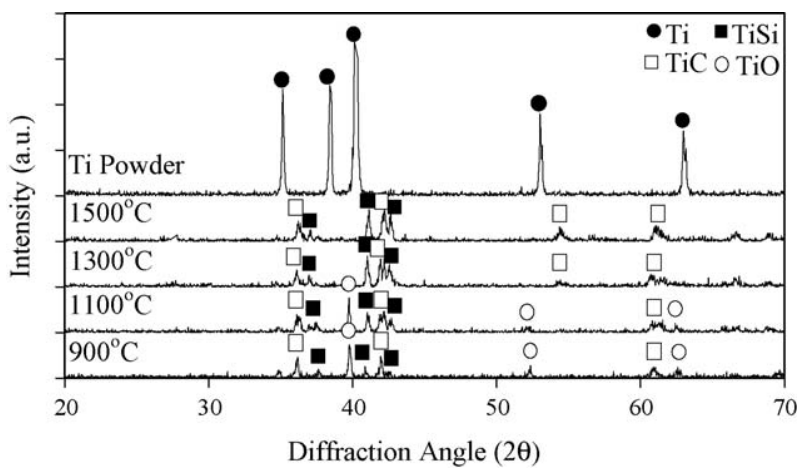

Fig. 8. X-ray diffraction patterns of $60 \mathrm{wt} . \%$ Ti/PMS pyrolyzed under Ar at various temperatures.

the XRD peaks of Ti filler are also given. Similar to PPS, pyrolysis of Ti/PMS green bodies yields the formation of TiC, TiSi, and $\mathrm{TiO}$ crystalline phases. At lower temperatures $\left(900-1100^{\circ} \mathrm{C}\right)$, the intensity of $\mathrm{TiO}$ phase is relatively high. However, at 1300 and $1500^{\circ} \mathrm{C}$, $\mathrm{TiO}$ phase is not detected. In this range, $\mathrm{TiC}$ and TiSi are the main phases. Hönack and Reidel ${ }^{14}$ studied the similar systems (pyrolysis of Ti/PMS composites) to investigate the influence of Ti-based filler additions on the thermal decomposition and phase developments of polysiloxanes. In their study, formation of $\mathrm{TiC}$ and $\mathrm{Ti}_{5} \mathrm{Si}_{3}$ crystalline phases were detected from the pyrolysis of $30 \mathrm{vol} . \%$ of Ti filled PMS at $1100^{\circ} \mathrm{C}$. However, no oxygen containing crystalline phases were detected contrary to the present work. The authors also concluded that the thermal decomposition and phase transformations of warm pressed polysiloxanes systems are affected by the addition of different fillers.

The microstructural developments were also monitored using SEM-EDX analysis. As an example, fracture surface SEM images of $80 \mathrm{wt} . \%$ Ti filled CMCs prepared at $900^{\circ} \mathrm{C}$ from Ti/PMS bodies are shown in Fig. 9. On these images, arbitrary points (A-E) were selected to determine the elemental distributions as tabulated in Table 1. As seen from the table, regions A and $\mathrm{E}$ are Ti rich and a matrix region (along $\mathrm{B}-\mathrm{D}$ ) with some compositional gradients may form between the adjacent Ti particulates. The matrix is expected to form from the decomposition products of the preceramic polymers and their reaction with $\mathrm{Ti}$ powder. Regions B and D may compose of $\mathrm{TiO}$, TiSi, or TiC phases while region $\mathrm{C}$ may be $\mathrm{SiOC}$ rich phases.

On the other hand, at pyrolysis temperatures above $1100^{\circ} \mathrm{C}$, the distinct phases observed at lower temperature cannot be

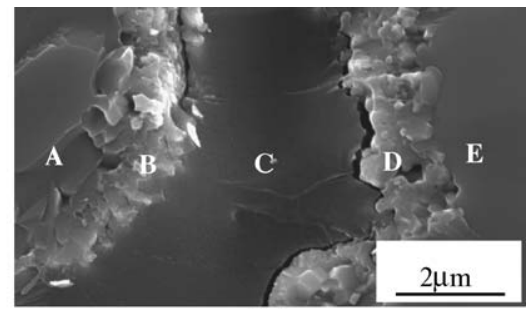

(b)

Fig. 9. Fracture surface SEM micrograph of $80 \mathrm{wt} . \%$ Ti filled CMC monolith prepared from Ti/PMS bodies at $900{ }^{\circ} \mathrm{C}((\mathrm{a}) 10000 \times$ and (b) $25000 \times$ magnifications of the same region). 


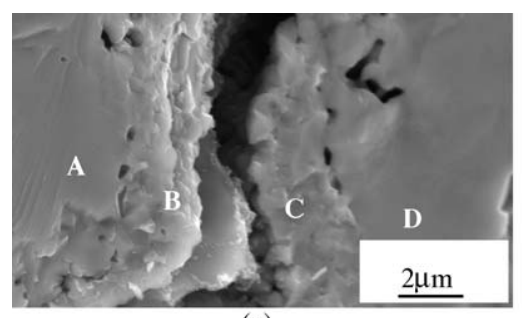

(a)

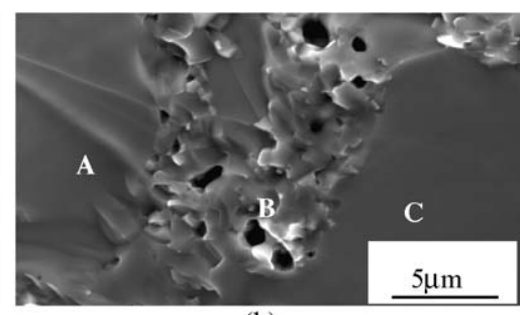

(b)

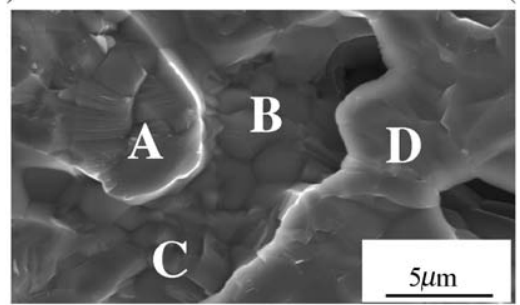

(c)

Fig. 10. Fracture surface SEM micrograph of $80 \mathrm{wt} . \%$ Ti filled CMC monolith prepared from Ti/PMS bodies at (a) $1100{ }^{\circ} \mathrm{C}$, (b) $1300{ }^{\circ} \mathrm{C}$, and (c) $1500^{\circ} \mathrm{C}$.

Table 1

Elemental distributions detected by SEM-EDX for the points labeled on the fracture surface image shown in Fig. 9

\begin{tabular}{llccl}
\hline Region & C (wt.\%) & Si (wt.\%) & 77 wt.\% & O (wt.\%) \\
\hline A & & 4 & 82 & 11 \\
B & 17 & 44 & 36 \\
C & 5 & 47 & 7 & 41 \\
D & 4 & 12 & 71 & 13 \\
E & 2 & 1 & 80 & 17 \\
\hline
\end{tabular}

detected evidently. Fig. 10 shows the fracture surfaces of 80 wt.\% Ti filled CMC monolith prepared from Ti/PMS at various temperatures. At elevated temperatures, compositional gradients and also the interphases with the matrix diminish due to extensive reaction/diffusion of the filler and pyrolysis products as can be followed from the EDX analysis shown in Table 2. This indicates more homogeneous distribution of the elements in the ceramic structure. In the microstructure, crystalline phases ( $\mathrm{TiC}$, $\mathrm{TiO}$, and $\mathrm{TiSi}$ ) are expected to be distributed within the SiOCbased matrix. Wei et al. ${ }^{17}$ also investigated the interfacial phase developments in active filler added polysiloxane-derived SiOC

Table 2

Elemental distributions detected by SEM-EDX for the points labeled on the fracture surface image shown in Fig. 10

\begin{tabular}{llllll}
\hline Sample & Region & C (wt.\%) & Si (wt.\%) & Ti (wt.\%) & O (wt.\%) \\
\hline a & A & 2 & 1 & 81 & 17 \\
& B & 2 & 19 & 57 & 22 \\
& C & 9 & 6 & 68 & 18 \\
& D & 2 & 1 & 75 & 22 \\
b & A & 2 & 0.25 & 90 & 8 \\
& B & 2 & & 90 & 5 \\
& C & 2 & 0.3 & 88 & 10 \\
c & A & 1 & 24 & 65 & 9 \\
& B & 6 & 0.4 & 73 & 21 \\
& C & 1 & 25 & 63 & 11 \\
& D & 2 & 0.4 & 74 & 23 \\
\hline
\end{tabular}

ceramics. It was found for Si particulate filled polymethylsiloxane (MK polymer) that at above $1000{ }^{\circ} \mathrm{C}$ interfacial reactions between the Si-filler particles and the SiOC matrix occurs and the filler surface is covered by a reaction zone of $\beta-\mathrm{SiC}$.

\subsection{Thermal transformations, ceramic yield and mass losses}

Pyrolytic conversion of polymeric precursors into $\mathrm{Si}-\mathrm{O}-\mathrm{C}$ systems leads to the formation of gaseous products that causes weight losses, volumetric changes and formation of microvoids. Figs. 11 and 12 show the weight changes of Ti-added PPS and PMS samples pyrolyzed at various pyrolysis temperatures, respectively. For pyrolysis in the range of $900-1500^{\circ} \mathrm{C}$, phenyl containing precursor PPS lose its weight of $22-27 \%$, while methyl containing precursor PMS lose $14-17 \%$ of the weight. As seen in Fig. 12, the average weight loss values for PMS at $1100{ }^{\circ} \mathrm{C}$ were found to be slightly lower (14\%) than those at $900{ }^{\circ} \mathrm{C}(15 \%)$. This slightly lower value at higher temperature ( $1 \%$ difference) may be considered within the experimental errors and the value at $1100{ }^{\circ} \mathrm{C}$ may be expected to be close to $15 \%$. The higher mass loss of PPS as compared to PMS is due to the lower ceramic yield and higher free carbon content of phenyl

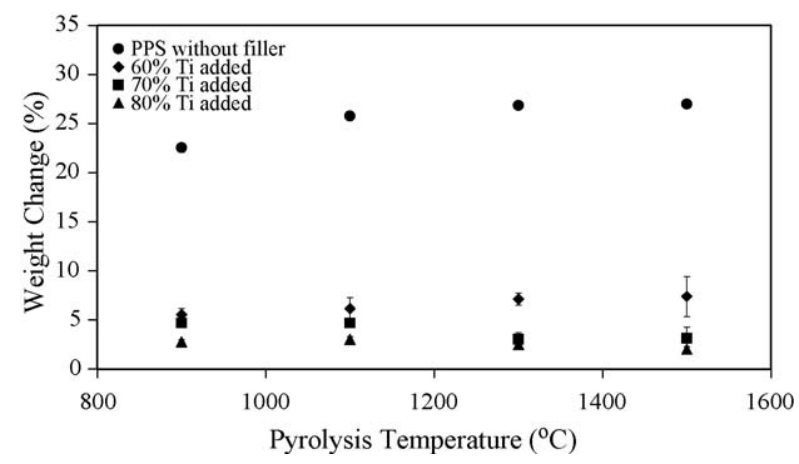

Fig. 11. Weight changes values as a function of pyrolysis temperature for samples made with Ti-added PPS. 


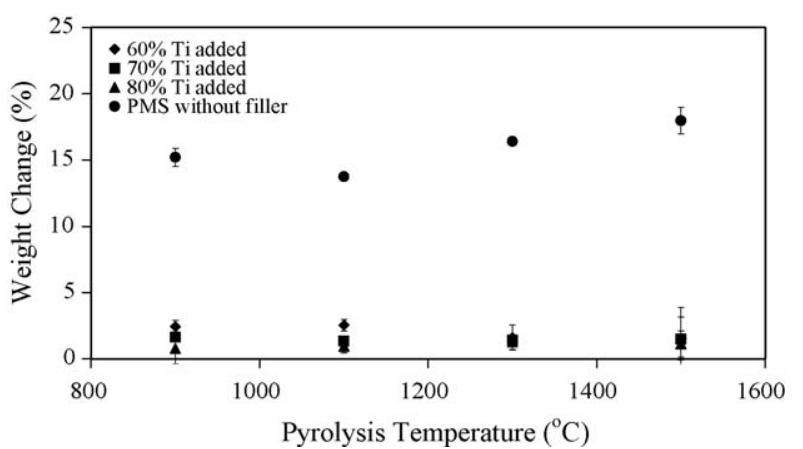

Fig. 12. Weight changes values as a function of pyrolysis temperature for samples made with Ti-added PMS.

containing siloxane relative to methyl containing precursor, as also reported in the literature. ${ }^{7}$ Greil ${ }^{4}$ reported a weight loss of 20-30 wt. \% up to $1400^{\circ} \mathrm{C}$ for phenyl and methyl containing polysiloxanes, similar to used within the present study. Harshe et al. ${ }^{7}$ also measured a mass loss value of $12.5 \%$ for PMS.

Weight changes are considerably affected by the incorporation of active Ti fillers into ceramic structure. Addition of Ti further reduces the values from $17 \%$ to at most $1.5 \%$ for PMS system. This is due to the reduction of the polymer ratio in the green composites and the reactions between the decomposition products of the polymer and filler particles. Similarly, Hönack and Reidel ${ }^{14}$ reported a $2.5 \mathrm{wt} . \%$ of total mass loss for $30 \mathrm{vol} . \%$ of Ti filled PMS systems pyrolyzed at $1100{ }^{\circ} \mathrm{C}$. Incorporation of Ti filler into PPS polymers reduces the weight change values to at most $2 \%$. It was also observed that although the filler ratio affects the weight change values of the Ti/PPS systems, it seems that there is no considerable effect on Ti/PMS system. Densification during organic to inorganic conversion can be controlled by incorporation of the active fillers by reducing the polymer ratio and promoting the reactions between the polymer decomposition products and the filler particles to control the shrinkage, porosity formation and microcracking.

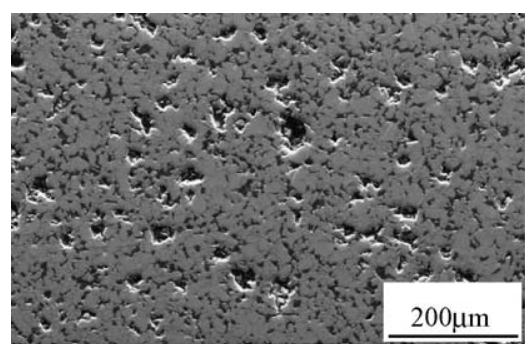

(a)
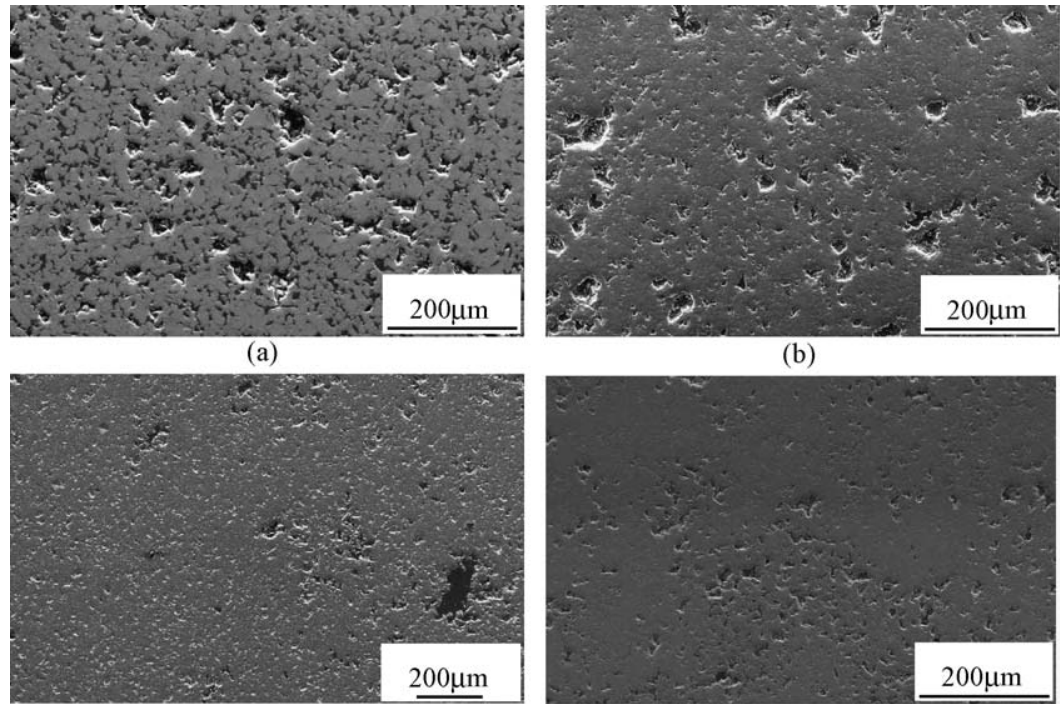

(c) (b)

Polished surface SEM images of CMCs made with $80 \mathrm{wt} . \%$ Ti filled PPS and PMS polymers pyrolyzed at various temperatures are illustrated in Figs. 13 and 14, respectively. As seen in the figures, as the pyrolysis temperatures increases a lower fraction of porosity is observed for PPS samples, while pore fraction is lower at about $1100{ }^{\circ} \mathrm{C}$ but increases at higher temperatures for PMS made composites. The formation of porosity is in agreement with density values of these samples. For PPS samples, the density values increases with increasing temperature and samples with low void content were formed; however, in PMS samples at $1500^{\circ} \mathrm{C}$ pore formation is increased and low density samples were obtained.

\subsection{Mechanical behavior of SiOC-based composites}

Hardness tests were carried out to evaluate the effects of pyrolysis temperature and filler addition into the precursor systems on the mechanical behavior of the composites. Figs. 15 and 16 show the hardness values of ceramics made with Ti-added PPS and PMS samples, respectively. Additionally, the hardness of the samples made with neat polymers is also given in the same figures. It was found that ceramics without filler addition reach the maximum hardness values $(8.88 \mathrm{GPa}$ made with PPS, $10.67 \mathrm{GPa}$ made with PMS) at $1100^{\circ} \mathrm{C}$, which is the optimum temperature for crack free samples with the least amount of porosity. However, the polymers exhibited distinct behavior by the incorporation of Ti particulates. For PPS, at low concentrations the addition of Ti reduces the hardness values; however, as the concentration of $\mathrm{Ti}$ and pyrolysis temperature increases higher values (up to $13.20 \pm 2.05 \mathrm{GPa}$ ) are measured as compared with those for ceramics without filler addition. On the other hand, for PMS system, it was found that the addition of Ti reduced the hardness of composites for all concentrations. The hardness of the samples made with PMS is lower than those made with neat PMS for all temperatures. Also, the hardness of composite samples of the PMS system remains almost constant

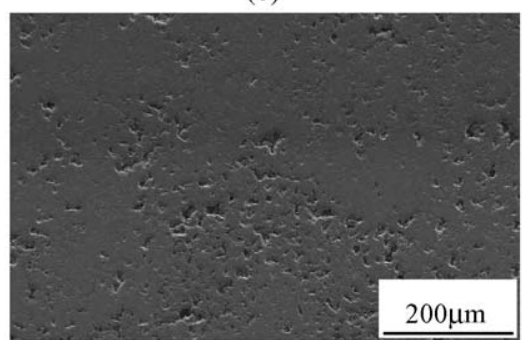

(d)

Fig. 13. SEM polished surface micrographs of $80 \mathrm{wt} . \%$ active Ti filled PPS pyrolyzed at various temperatures (a) $900^{\circ} \mathrm{C},\left(\right.$ b) $1100^{\circ} \mathrm{C}$, (c) $1300^{\circ} \mathrm{C}$, and (d) $1500^{\circ} \mathrm{C}$. 


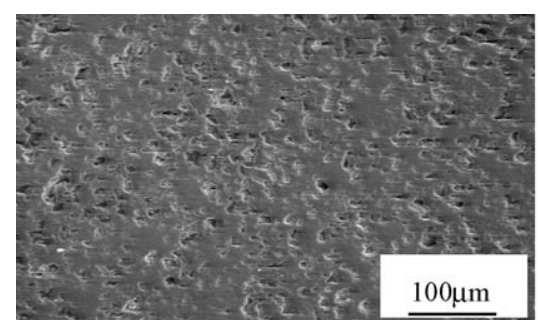

(a)

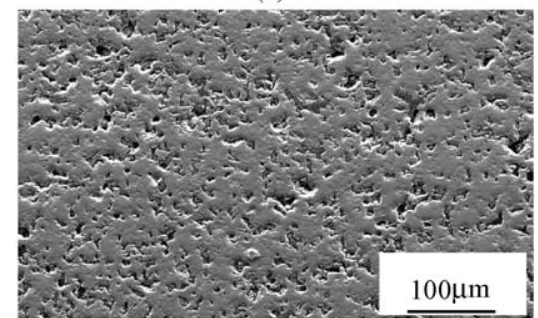

(c)

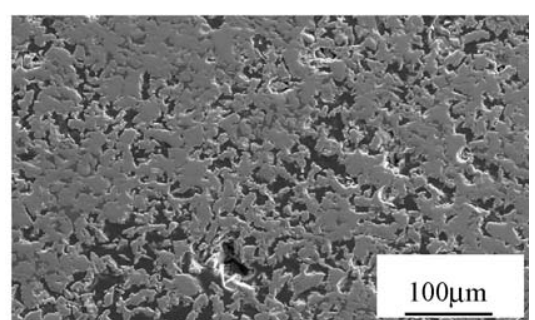

(b)

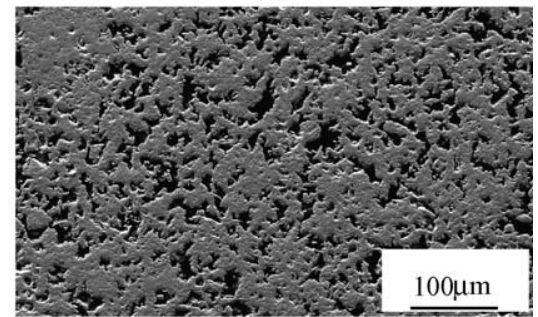

(d)

Fig. 14. SEM polished surface micrographs of $80 \mathrm{wt} . \%$ active Ti filled PMS pyrolyzed at various temperatures (a) $900^{\circ} \mathrm{C}$, (b) $1100^{\circ} \mathrm{C}$, (c) $1300^{\circ} \mathrm{C}$, and (d) $1500^{\circ} \mathrm{C}$.

at different temperatures. It is known that the Vickers hardness values of glassy materials are typically given in between 5 and $10 \mathrm{GPa}$. The ceramics made with neat PPS and PMS samples yield very comparable results. By the addition of Ti powders, the values reach up to $14 \mathrm{GPa}$ for composites made with PPS samples. These values are in the range that the developed materials have potential to be utilized within various applications.

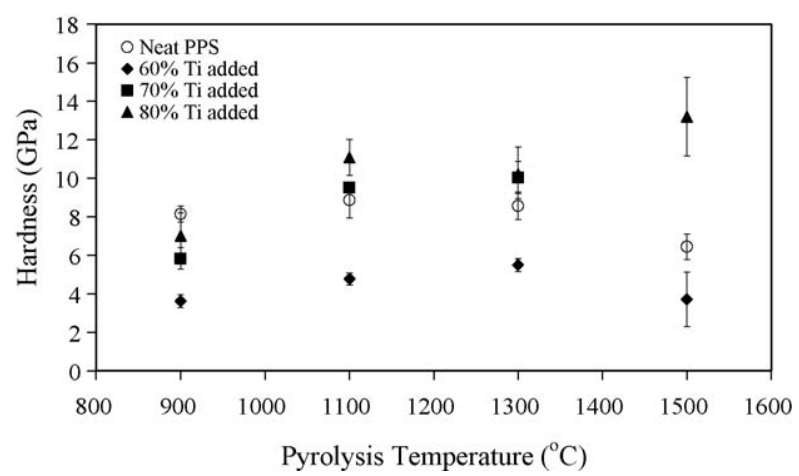

Fig. 15. Vickers hardness values as a function of pyrolysis temperature for neat ceramics and composites made with various concentration of Ti-added to PPS.

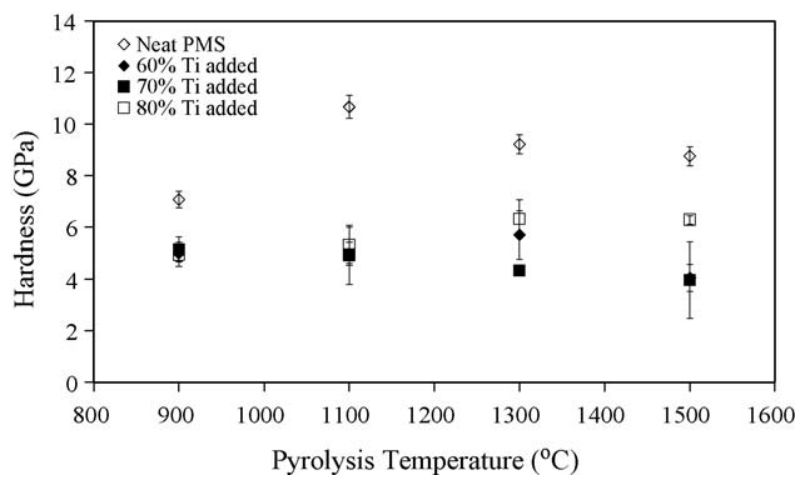

Fig. 16. Vickers hardness values as a function of pyrolysis temperature for neat ceramics and composites made with various concentration of Ti-added to PMS.

\section{Conclusions}

Active filler incorporated silicon oxycarbide-based ceramic composites were developed based on the pyrolytic conversion of -phenyl and -methyl containing polysiloxanes. The effects of filler ratio and pyrolysis temperature on the phase development and mechanical properties of the composites were investigated. X-ray diffraction measurements revealed that the thermal transformation of the polymers without filler addition yields amorphous silicon oxycarbide ceramics at temperatures below $1300^{\circ} \mathrm{C}$; however, at higher temperatures crystalline $\beta$-SiC phases formed. SiOC phase formations were confirmed with SEM-EDX analysis that were performed on fracture surfaces of neat and composite ceramic samples. Neat poly(phenyl)siloxane samples showed the formation of pores increasing with increasing pyrolysis temperature; however, a less fraction of pore formations observed in poly (methyl)siloxanes. This is associated with the lower ceramic yield and higher free carbon content of phenyl containing siloxane relative to methyl containing precursor. The decompositions of the polymers and release of hydrocarbons results with porosity formations.

Active Ti fillers were added into the polymers to compensate the negative mass loss and shrinkage effect due to the decomposition of the polymers. Active fillers compensate the mass losses with both decreasing the polymer ratio and with reaction of active filler and decomposition products of the polysiloxanes. XRD analysis revealed that $\mathrm{TiC}, \mathrm{TiSi}$, and $\mathrm{TiO}$ phases formed within the amorphous matrix due to the reactions between the active Ti particulates and the polymers. It was found that there is considerable effect of the addition of fillers on the thermal transformations and therefore on the mass loss and densifications. Although neat PPS and PMS samples show weight loss values of about 25 and $15 \%$, respectively, incorporation of active fillers decreases these values nearly to $2 \%$. The results also imply that pyrolysis temperature has some significant effect on the densification behavior. At higher pyrolysis temperatures the formation 
of pores was detectable in Ti/PMS samples while a relatively smooth surface was observed in Ti/PPS systems.

The pyrolysis products of the polymer precursors exhibited distinct mechanical behavior by the incorporation of Ti particulates. With addition of Ti into PPS increased the hardness values with increasing the filler ratio and reached to $\sim 14 \mathrm{GPa}$, which is close to the hardness of some technical ceramics such as alumina. However, addition of Ti into PMS polymer decreases hardness values for all compositions and this is in agreement with microstructural features of the samples.

\section{Acknowledgements}

The authors would like to acknowledge the Scientific and Research Council of Turkey (TÜBİTAK) for the financial support of the MISAG 215 project out of which this study has emerged.

\section{References}

1. Mutin, P. H., Control of the composition and structure of silicon oxycarbide and oxynitride glasses derived from polysiloxane precursors. $J$. Sol-Gel Sci. Technol., 1999, 14, 27-38.

2. Radovanovic, E., Gozzi, M. F., Gonçalves, M. C. and Yoshida, I. V. P., Silicon oxycarbide glasses from silicon networks. J. Non-Cryst. Solids, 1999, 248, 37-48.

3. Schiavon, M. A., Redondo, S. U. A., Pina, S. R. O. and Yoshida, I. V. P., Investigation on kinetics of thermal decomposition in polysiloxane networks used as precursors of silicon oxycarbide glasses. J. Non-Cryst. Solids, 2002, 304, 92-100.

4. Greil, P., Near net shape manufacturing of polymer derived ceramics. $J$. Eur. Ceram. Soc., 1998, 18, 1905-1914.

5. Kaindl, A., Lehner, W., Greil, P. and Kim, D. J., Polymer-filler derived $\mathrm{Mo}_{2} \mathrm{C}$ ceramics. Mater. Sci. Eng., 1999, A260, 101-107.
6. Greil, P., Near net shape manufacturing of ceramics. Mater. Chem. Phys., 1999, 61, 64-68.

7. Harshe, R., Balan, C. and Riedel, R., Amorphous Si(Al)OC ceramic from polysiloxanes: bulk ceramic processing, crystallization behavior and applications. J. Eur. Ceram. Soc., 2004, 24, 3471-3482.

8. Herzoga, A., Thunemann, M., Vogta, U. and Beffort, O., Novel application of ceramic precursors for the fabrication of composites. J. Eur. Ceram. Soc., 2005, 25, 187-192.

9. Naslain, R., Design, preparation and properties of non-oxide CMCs for application in engines and nuclear reactors: an overview. Compos. Sci. Technol., 2004, 64, 155-170.

10. Michalet, T., Parlier, M., Addad, A., Duclos, R. and Crampon, J., Formation at low temperature with low shrinkage of polymer/Al/ $/ \mathrm{Al}_{2} \mathrm{O}_{3}$ derived. Ceram. Int., 2001, 27, 315-319.

11. Soraru, G. D., Kleebe, H. J., Ceccato, R. and Pederiva, L., Development of mullite-SiC nanocomposites by pyrolysis of filled polymethylsiloxane gels. J. Eur. Ceram. Soc., 2000, 20, 2509-2517.

12. Schiavon, M. A., Radovanovic, E. and Yoshida, I. V. P., Microstructural characterisation of monolithic ceramic matrix composites from polysiloxane and SiC powder. Powder Technol., 2002, 123, 232-241.

13. Michalet, T., Parlier, M., Beclin, F., Duclos, R. and Crampon, J., Elaboration of low shrinkage mullite by active filler controlled pyrolysis of siloxanes. J. Eur. Ceram. Soc., 2002, 22, 143-152.

14. Hönack, F. and Reidel, R., Influence of Ti-based fillers on the thermal decomposition and phase development of polysiloxanes derived materials. Adv. Eng. Mater., 2003, 5, 122-125.

15. Brus, J., Kolar, F., Machovic, V. and Svitilova, J., Structure of silicon oxycarbide glasses derived from poly(methylsiloxane) and poly[methyl(phenyl)siloxane] precursors. J. Non-Cryst. Solids, 2001, 289, 62-74.

16. Schiavon, M. A., Soraru, G. D. and Yoshida, I. V. P., Synthesis of a polycyclic silazene network and its evaluation to silicon carbonitride glass. $J$. Non-Cryst. Solids, 2002, 304, 76-83.

17. Wei, G., Pippel, E., Wolersdorf, J., Scheffler, M. and Greil, P., Interfacial $\mathrm{SiC}$ formation in polysiloxanes-derived Si-O-C ceramics. Mater. Chem. Phys., 2002, 73, 281-289. 